\title{
HUBUNGAN KEPEMIMPINAN DENGAN KINERJA KADER IMUNISASI DASAR CAMPAK PADA BAYI DI WILAYAH KERJA PUSKESMAS PADANG BULAN TAHUN 2019
}

\author{
Sri Yanti Purba ${ }^{1}$, Rapael Ginting ${ }^{2}$ \\ ${ }^{1}$ Fakultas Kesehatan Masyarakat, Universitas Prima Indonesia, Medan \\ ${ }^{2}$ Dosen Fakultas Kesehatan Masyarakat, Universitas Prima Indonesia, \\ Medan \\ E-mail : Purbasriyanti@yahoo.com \\ DOI : https://doi.org/10.35451/jkg.v2i1.221
}

\section{Abstrack}

The posyandu cadre is a volunteer chosen from the community and to help develop community health by carrying out activities at the posyandu which include increasing immunization coverage. Cadre performance is the result / effort that has been done in the midst of the community. Based on the data obtained by researchers from the Padang Bulan Community Health Center the sample of this study were 75 cadres consisting of 6 Kelurahan namely: Kelurahan Petisah Hulu of 20 cadres, Kelurahan Darat by 5 cadres, Kelurahan Titi Rantai as many as 15 cadres, Padang Bulan Kelurahan as many as 10 cadres, Merdeka Village as many as 15 cadres, and Babura Village as many as 10 people. The purpose of this study was to look at the relationship between variables Openness, Empathy, Supporting Attitudes, and Measles Cadre Immunization Performance in infants. The research used is analytic descriptive and uses cross sectional design. Data were analyzed using Chi Square Test ( $C I=95 \%, a$ 0.05). The results of data analysis showed that there was a relationship between Openness and Cadre Performance ( $p$ value $=$ $0,000>0.05)$, there was a relationship between Empathy and Cadre Performance ( $p$ value $=0,000>0.05$ ), and there was a relationship between variables Supporting Attitudes with Cadre Performance ( $p$ value $=0,000>0.05$ ). Therefore, it is expected that respondents will further enhance their understanding of what respondents should do in the field before the posyandu is conducted and after the posyandu is done in the field so as to improve the performance of the posyandu cadres.

\section{Keywords: Openness, Empathy, Supporting Attitudes, Cadre Performance}

\section{PENDAHULUAN}

Pusat Kesehatan Masyarakat yang lebih dikenal oleh masyarakat sebagai Puskesmas merupakan organisasi fungsional yang menyelenggarakan upaya kesehatan masyarakat yang bersifat menyeluruh, terpadu, merata dan terjangkau oleh masyarakat luas dengan biaya yang dapat dipikul oleh pemerintah maupun masyarakat. Walaupun upaya pelayanan kesehatan di Puskesmas lebih menitikberatkan kepada masyarakat 
Jurnal Kesehatan Masyarakat \& Gizi, e-ISSN: 2655-0849

Vol. 2 No.1 Edisi Mei-Oktober 2019

https://ejournal.medistra.ac.id/index.php/JKG

Received: 05 Oktober 2019 :: Accepted: 14 Oktober 2019 :: Published: 31 Oktober 2019

tingkat menengah ke bawah bukan berarti dapat mengabaikan mutu pelayanan kepada orang perorangan.Program dan upaya kesehatan yang diselenggarakan oleh puskesmas merupakan program pokok (public health essential) yang wajib dilaksanakan oleh pemerintah untuk mewujudkan kesejahteraan masyarakat (Herlambang, 2016).

$$
\text { Kepemimpinan }
$$

adalah

kekuatan untuk menggunakan dan mempengaruhi, memberi inspirasi seseorang atau kelompok untuk mencapai tujuan/sasaran tertentu.Sifat atau ciri-ciri pemimpin yang efektif sangat jelas kelihatannya, bahwa pemimpin memainkan peran yang sangat strategis dalam memutuskan organisasi, kelompok ataupun masyarakat lainnya untuk mencapai suatu tujuan tertentu yang telah ditetapkan (Mulyadi 2018).

Kasus campak di Indonesia masih sering terjadi meskipun telah berhasil direduksi lebih dari 180.000 kasus di tahun 1990 menjadi sekitar 20.000 kasus di tahun 2010. Sebagai upaya mengurangi terjadinya penularan penyakit ini dilakukan pemberian imunisasi rutin dan pemberian imunisasi bertahap melalui BIAS (Bulan Imunisasi Anak Sekolah) sebagai booster dan menurunkan angka kematiannya sebesar 90 persen.Angka kematian penyakit campak di negara berkembang mendekati satu kematian perseribu kasus.Di negara miskin angka kematian berkisar 10\%.Kejadian tersebut banyak dialami pada penduduk yang kurang gizi dan rendahnya perawatan kesehatan. Jumlah desa yang telah mencapai Universal Child Immunization (UCI) 68,3 persen dari 65.781 desa pada tahun 2008. Setelah program akselerasi dijalankan tahun 2010 mencapai kenaikan sebesar 75,3\% dari 75.990 desa. Program imunisasi nasional yaitu imunisasi yang diberikan pada bayi balita dan booster imunisasi pada anak murid Sekolah Dasar kelas 1,2,dan 3. Program imunisasi di Indonesia sudah mencapai Universal Child Imunization (UCI). Pada tahun 1990 telah mencapai lebih dari $80 \%$ dan tahun 2007 cakupan imunisasi. BCG, DPT 3. Polio 3 dan campak menunjukkan peningkatan sebesar 90\%, 88\%, $85 \%$.dan 87\% (Pracoyo, 2013).

Puskesmas Padang Bulan merupakan salah satu Puskesmas yang ada di Kota Medan dan Puskesmas yang terakreditasi dalam upaya kesehatan tingkat pertama di wilayah Kota Medan. Pada Puskesmas Padang Bulan memiliki sebanyak 75 orang kader posyandu imunisasi dasar campak yang terdiri dari 6 kelurahan yaitu: Kelurahan Babura sebanyak 10 kader, Kelurahan Titi Rantai sebanyak 15 orang, Kelurahan Merdeka sebanyak 15 orang, Kelurahan Petisah Hulu sebanyak 20 orang, Kelurahan Padang Bulan sebanyak 10 orang, dan di Kelurahan Darat sebanyak 5 orang, dan memiliki 15 posyandu (Profile Puskesmas Padang Bulan,2019).

Berdasarkan survey awal di wilayah kerja Puskesmas Padang Bulan pada tanggal 20 September 2018, terhadap kader di Puskesmas Padang Bulan menyatakan bahwa kinerja kader dilapangan belum sesuai dengan harapan, dan pada saat saya turun kelapangan bersama pemimpin dan petugas kesehatannya saya melihat langsung bahwa memang kadernya kurang aktif dilapangan. Kader disana sudah memberitahukan kepada ibu-ibu yang mempunyai bayi agar membawa bayinya untuk membawa bayinya keposyandu supaya diimunisasi tetapi kadernya tidak mengingatkan/mengajak 
kembali kepada ibu-ibu itusupaya datang ke posyandu atau kepuskesmas untuk membawanya bayinya untuk diimunisasi dan pada saat dilapangan posyandu sudah berjalan ibu- ibu sudah datang membawa bayinya untuk diimunisasi namun para kadernya hanya sedikit yang datang dikarenakan urusan rumah tangga yang belum siap dikerjakan.

\section{METODE}

Penelitian

ini

menggunakan metode deskriptif analitik dengan Rancangan penelitian ini bersifat cross sectional yang bertujuan untuk mengetahui hubungan kepemimpinan dengan kinerja kader imunisasi dasar campak pada bayi di wilayah kerja Puskesmas Padang Bulan Tahun 2019.

Lokasi Penelitian ini dilakukan di Puskesmas Padang Bulan Kota Medan Tahun 2019. Penelitian ini dilaksanakn pada bulan Juni Tahun 2019 di Puskesmas Padang Bulan. Populasi adalah keseluruhan objek penelitian yang diteliti (Notoatmodjo, 2012). Populasi dalam penelitian ini adalah 75 kader (Januari-Desember) di Puskesmas Padang Bulan Tahun 2019. Tekhnik sampling yang digunakan pada penelitian ini adalah keseluruhan kader posyandu yaitu semua populasi dijadikan sampel. Sampel pada penelitian ini yaitu sebanyak 75 kader di Puskesmas Padang Bulan Tahun 2019.

Data yang dikumpulkan terdiri dari data primer dan data sekunder. Data primer adalah data yang diperoleh langsung dari subjek penelitian dengan alat pengukuran atau pengambilan data, langsung pada subjek sebagai sumber informasi yang dicari. Data primer pada penelitian ini diperoeh dari hasil pengamatan langsung peneiti dan kuesioner dengan responden yaitu kader posyandu imunisasi dasar campak pada bayi di Puskesmas Padang Bulan Tahun 2019. Data sekunder ini diperoleh dari jumlah kader di Puskesmas Padang Bulan Tahun 2019. Analisis data penelitian ini terdiri dari analisis univariat dan analisis bivariat diolah menggunakan uji chi-square dengan taraf signifikan sebesar $95 \%$ (a) atau derajat kepercayaan 0,05\%. (Notoadmojo, 2012).

\section{HASIL PENELITIAN Analisis Univariat}

\section{Tabel 1 Distribusi Frekuensi Karakteristik Responden Berdasarkan Umur, Pendidikan dan Pekerjaan Kader di Wilayah Kerja Puskesmas Padang Bulan Tahun 2019}

Berdasarkan tabel 1 diperoleh

\begin{tabular}{llcc}
\hline No & \multicolumn{1}{c}{$\begin{array}{c}\text { Karakte } \\
\text { ristik }\end{array}$} & $\begin{array}{c}\text { Jum } \\
\text { Lah } \\
\text { (n) }\end{array}$ & $\begin{array}{c}\text { Persen } \\
\text { tase } \\
\text { (\%) }\end{array}$ \\
\hline 1 & Umur & & \\
& $36-41$ thn & 5 & 6,7 \\
& $42-47$ thn & 16 & 21,3 \\
& $48-53$ thn & 54 & 72,0 \\
\hline & Total & $\mathbf{7 5}$ & $\mathbf{1 0 0 , 0}$ \\
\hline 2 & Pendidikan & & \\
& SD & 2 & 2,7 \\
& SMP & 31 & 41,3 \\
& SMA & 37 & 49,3 \\
& Perguruan & 5 & 6,7 \\
& Tinggi & & \\
\hline & Total & $\mathbf{7 5}$ & $\mathbf{1 0 0 , 0}$ \\
\hline 3 & Pekerjaan & & \\
& Tidak Bekerji & 40 & 53,3 \\
& Wiraswasta & 30 & 40,0 \\
& PNS & 5 & 6,7 \\
\hline & Total & $\mathbf{4 2}$ & $\mathbf{1 0 0 , 0}$ \\
\hline
\end{tabular}

distribusi frekuensi kelompok umur responden, mayoritas responden adalah kelompok umur 48-53 tahun sebanyak 54 orang $(74,0 \%)$ dan minoritas adalah kelompok umur 36-41 tahun tahun sebanyak 5 orang $(6,7 \%)$.

Berdasarkan distribusi frekuensi pendidikan responden, mayoritas adalah 
Jurnal Kesehatan Masyarakat \& Gizi, e-ISSN: 2655-0849

Vol. 2 No.1 Edisi Mei-Oktober 2019

https://ejournal.medistra.ac.id/index.php/JKG

$===========================================================+$
Received: 05 Oktober 2019 :: Accepted: 14 Oktober 2019 :: Published: 31 Oktober 2019

pendidikan SMA sebanyak 37 orang $(49,3 \%)$ dan minoritas adalah pendidikan SD sebanyak 2 orang $(2,7 \%)$.
Berdasarkan distribusi frekuensi pekerjaan, mayoritas responden adalah tidak bekerja sebanyak 40 orang $(53,3 \%)$ dan minoritas responden adalah PNS sebanyak 5 orang $(6,7 \%)$.

Tabel 2 Distribusi Frekuensi Berdasarkan Keterbukaan (Openness), Empati (Empaty), Sikap Mendukung (Supportif), dan Kineja Kader Posyandu di Wilayah Kerja Puskesmas Padang Bulan Tahun 2019

\begin{tabular}{llll}
\hline No & Variabel & Jumlah (n) & Persentase (\%) \\
\hline 1 & Keterbukaan (Openness) & 69 & \\
& Ya & 6 & 92,0 \\
& Tidak & $\mathbf{7 5}$ & 8,0 \\
\hline & Total & $\mathbf{1 0 0 , 0}$ \\
\hline 2 & Empati (Empaty) & 28 & 37,3 \\
& Ya & 47 & 62,7 \\
\hline & Tidak & $\mathbf{7 5}$ & $\mathbf{1 0 0 , 0}$ \\
\hline \multirow{2}{*}{ Total } & Sikap Mendukung (Supportif) & & \\
& Ya & 51 & 68,0 \\
& Tidak & 24 & 32,0 \\
\hline & Total & $\mathbf{7 5}$ & $\mathbf{1 0 0 , 0}$ \\
\hline 4 & Kinerja Kader Posyandu & & \\
& Ya & 50 & 66,7 \\
& Tidak & 25 & 33,3 \\
\hline & Total & $\mathbf{7 5}$ & $\mathbf{1 0 0 , 0}$ \\
\hline
\end{tabular}

Pada tabel 2 diatas dapat dilihat bahwa berdasarkan keterbukaan (openness), mayoritas responden adalah dengan kategori ya sebanyak 69 orang $(92,0 \%)$ dan minoritas responden adalah dengan kategori tidak sebanyak 6 orang $(8,0 \%)$.

Berdasarkan empati (empaty), mayoritas responden adalah dengan kategori tidak sebanyak 47 orang $(62,7 \%)$ dan minoritas responden adalah dengan kategori ya sebanyak 28 orang $(37,3 \%)$.
Berdasarkan sikap mendukung (supportif), mayoritas responden adalah dengan kategori ya sebanyak 51 orang $(68,0)$ dan minoritas responden adalah dengan kategori tidak adalah sebanyak 24 orang $(32,0 \%)$.

Berdasarkan kinerja kader posyandu, mayoritas responden adalah dengan kategori ya sebanyak 50 orang $(66,7 \%)$ dan minoritas responden adalah dengan kategori tidak sebanyak 25 orang $(33,3 \%)$. 
Tabel 3 Hubungan Keterbukaan (Openness, Empati (Empaty), Sikap Mendukung (Supportif) Dengan Kinerja Kader Imunisasi Dasar Campak Pada Bayi Di Wilayah Kerja Puskesmas Padang Bulan Tahun 2019

\begin{tabular}{|c|c|c|c|c|c|c|c|}
\hline \multirow{3}{*}{$\begin{array}{l}\text { Keterbukaa } \\
\text { (Openness) }\end{array}$} & \multirow[b]{2}{*}{ Ya } & \multicolumn{5}{|c|}{ Kinerja Kader } & \multirow[t]{3}{*}{ p Value } \\
\hline & & \multicolumn{3}{|c|}{ Tidak } & \multicolumn{2}{|c|}{ Total } & \\
\hline & $\mathbf{N}$ & $\%$ & $\mathbf{N}$ & $\%$ & $\mathbf{N}$ & $\%$ & \\
\hline Terbuka & 50 & 72,5 & 19 & 27,5 & 69 & 100 & 0,000 \\
\hline $\begin{array}{l}\text { Tidak } \\
\text { Terbuka }\end{array}$ & 0 & 0,0 & 6 & 100 & 6 & 100 & \\
\hline
\end{tabular}

\begin{tabular}{|c|c|c|c|c|c|c|c|}
\hline \multirow{3}{*}{$\begin{array}{l}\text { Empati } \\
\text { (Empaty) }\end{array}$} & \multicolumn{6}{|c|}{ Kinerja Kader } & \multirow[t]{3}{*}{ p Value } \\
\hline & \multicolumn{2}{|l|}{$\mathbf{Y a}$} & \multicolumn{2}{|l|}{ Tidak } & \multicolumn{2}{|c|}{ Total } & \\
\hline & $\mathbf{N}$ & $\%$ & $\mathbf{N}$ & $\%$ & $\mathbf{N}$ & $\%$ & \\
\hline Empati & 28 & 100 & 0 & 0,0 & 28 & 100 & 0,000 \\
\hline Tidak Empa' & 22 & 46,8 & 25 & 53,2 & 47 & 100 & \\
\hline
\end{tabular}

\begin{tabular}{|c|c|c|c|c|c|c|c|}
\hline \multirow{3}{*}{$\begin{array}{l}\text { Sikap } \\
\text { Mendukung } \\
\text { (Supportif) }\end{array}$} & \multicolumn{6}{|c|}{ Kinerja Kader } & \multirow{3}{*}{ p Value } \\
\hline & \multicolumn{2}{|l|}{ Ya } & \multicolumn{2}{|c|}{ Tidak } & \multicolumn{2}{|c|}{ Total } & \\
\hline & $\mathbf{N}$ & $\%$ & $\mathbf{N}$ & $\%$ & $\mathbf{N}$ & $\%$ & \\
\hline Mendukung & 50 & 98,0 & 1 & 2,0 & 51 & 100 & 0,000 \\
\hline $\begin{array}{l}\text { Tidak } \\
\text { Mendukung }\end{array}$ & 0 & 0,0 & 24 & 100 & 24 & 100 & \\
\hline
\end{tabular}

\section{PEMBAHASAN}

Hubungan Keterbukaan (Openness) Dengan Kinerja Kader Imunisasi Dasar Campak Pada Bayi Di Wilayah Kerja Puskesmas Padang Bulan Tahun 2019

Berdasarkan hasil uji statistic menggunakan Uji Chi-Square diperoleh $p$ value $=0,000$ ( $p$ value $<0,05)$, artinya $\mathrm{Ho}$ ditolak dan Ha diterima, ini menunjukkan bahwa ada hubungan yang signifikan antara Keterbukaan (Openness) Dengan Kinerja Kader Imunisasi Dasar Campak Pada Bayi di Wilayah Kerja Puskesmas Padang Bulan Tahun 2019. Diketahui bahwa dari 69 responden yang terbuka, mayoritas responden menjawab ya adalah sebanyak
50 responden $(72,5 \%)$ dan minoritas responden menjawab tidak adalah sebanyak 19 responden (27,5\%). Dari seluruh responden yang tidak terbuka adalah sebanyak 6 responden (100\%) adalah menjawab tidak.

Berdasarkan observasi yang dilakukan peneliti menyimpulkan bahwa Keterbukaan (Openness) memiliki hubungan Dengan Kinerja Kader Imunisasi Dasar Campak Pada Bayi di Wilayah Kerja Puskesmas Padang Bulan.

Hasil penelitian ini sejalan dengan penelitian Nurfitriani (2010) di Wilayah Kerja Puskesmas Tanete Kecamatan 
Bulukumba Kabupaten Bulukumba, dengan judul faktor-faktor yang mempengaruhi keaktifan kader posyandu di puskesmas tanete kecamatan bulukumba kabupaten bulukumba tahun 2010 dengan sampel sebanyak 45 responden dengan menggunakan pendekatan cross sectional, terdapat nilai $p$ value $=0,002(p<0,05)$. Artinya ada hubungan antara keterbukaan dengan kinerja kader posyandu.

Berdasarkan tabel diatas dapat dilihat bahwa Keterbukaan (Openness) dari kader sudah baik namun masih ada yang tidak terbuka ini disebabkan oleh kurang terbukanya antara pemimpin dengan kader. Sehingga terjadi kesenjangan antara pemimpin dengan kader dan mengakibatkan kurangnya kinerja kader dilapangan.

Menurut asumsi peneliti hal tersebut membuktikan bahwa kinerja kader posyandu juga berhubungan dengan keterbukaan. Keterbukaan atau sikap terbuka sangat berpengaruh dalam menumbuhkan komunikasi antarpribadi yang efektif. Berdasarkan hasil penelitian yang telah dilakukan bahwa Pemimpin harus memiliki sifat keterbukaan (openness) terhadap kinerja posyandu imunisasi, pemimpin harus selalu terbuka terhadap kader dan selalu menyediakan waktu untuk bisa saling bertukar pikiran supaya pemimpin itu tau apa saja kendala yang dihadapi kader posyandu dilapangan dan bagai mana cara mengatasi hal tersebut dan pemimpin harus memberikan fasilitas yang memadai terhadap kader seperti mengirimkan kader kepelatihanpelatihan kesehatan, memberikan buku panduan dan mengikuti seminar-seminar kesehatan. Pemimpin juga harus tau alasan kader kenapa dia mau menjadi kader dan kenapa menjadi kader karena lingkungan membutuhkan seorang kader.

Hubungan Empati (Empaty) Dengan Kinerja Kader Imunisasi Dasar Campak

\section{Pada Bayi Di Wilayah Kerja Puskesmas Padang Bulan Tahun 2019}

Berdasarkan hasil uji statistic menggunakan Uji Chi-Square diperoleh $p$ value $=0,000$ ( $p$ value $<0,05)$, artinya Ho ditolak dan Ha diterima, ini menunjukkan bahwa ada hubungan yang signifikan antara Empati (Empaty) dengan Kinerja Kader Imunisasi Dasar Campak pada Bayi di Wilayah Kerja Puskesmas Padang Bulan Tahun 2019. Diketahui bahwa dari 28 responden dengan kategori empati, seluruh responden adalah sebanyak 28 orang $(100 \%)$ adalah menjawab ya. Dari 47 responden dengan kategori tidak empati, mayoritas responden menjawan ya adalah sebanyak 22 responden $(46,8 \%)$ dan minoritas responden menjawab tidak adalah sebanyak 25 responden $(53,2 \%)$.

Berdasarkan observasi yang dilakukan peneliti menyimpulkan bahwa Empati (Empaty) memiliki hubungan Dengan Kinerja Kader Imunisasi Dasar Campak Pada Bayi di Wilayah Kerja Puskesmas Padang Bulan.

Hasil penelitian ini sejalan dengan penelitian Ade (2017) di kabupaten ponorogo, dengan judul hubungan sikap, empati dan motivasi kerja dengan kinerja kader posyandu di kabupaten ponorogo dengan sampel sebanyak 35 orang dengan menggunakan pendekatan kuantitatif yang didukung data data kualitatif, terdapat nilai $p$ value $=0,000(p<0,05)$. Artinya ada hubungan antara empati dengan kinerja kader posyandu.

Berdasarkan tabel diatas dapat dilihat bahwa Empati (Empaty) dari kader sudah baik namun masih ada yang tidak empati ini disebabkan oleh kurangnya kepedulian antara pemimpin dengan kader. Pemimpin juga jarang memberikan arahan dan bimbingan kepada para kader dikarenakan pemimpin terlalu sibuk sehingga para kader mengalami kesulitan pada saat posyandu berjalan dilapangan. 
Received: 05 Oktober 2019 :: Accepted: 14 Oktober 2019 :: Published: 31 Oktober 2019

Menurut asumsi peneliti hal tersebut membuktikan bahwa kinerja kader posyandu juga berhubungan dengan empati. Berdasarkan hasil penelitian yang telah dilakukan bahwa Pemimpin itu harus memiliki rasa empati (empaty) terhadap kinerja kader posyandu imunisasi, pemimpin harus memiliki rasa kepedulian dan perhatian terhadap kinerja kader posyandu karena akan berpengaruh terhadap kemauan dan perilaku kader untuk mengaitkan kegiatan posyandu, sehingga akan mempengaruhi terlaksananya program kerja posyandu. Pemimpin harus tau dan peduli apa yang dilakukan para kader dilapangan apakah kader selalu peduli dengan kegiatan posyandu dilapangan dan apakan para kader selalu mengingatkan kembali kepada orang tua bayi untuk membawa bayinya keposyandu berikutnya untuk diimunisasi supaya kinerja kader dilapangan tercapai sesuai dengan yang diharapkan atau lebih baik kedepannya.

\section{Hubungan Sikap Mendukung (Supportif) Dengan Kinerja Kader Imunisasi Dasar Campak Pada Bayi Di Wilayah Kerja Puskesmas Padang Bulan Tahun 2019}

Berdasarkan hasil uji statistic menggunakan Uji Chi-Square diperoleh $p$ value $=0,000$ ( $p$ value $<0,05)$, artinya $\mathrm{Ho}$ ditolakdan $\mathrm{Ha}$ diterima, ini menunjukkan bahwa ada hubungan yang signifikan antara Sikap Mendukung (Supportif) dengan Kinerja Kader Imunisasi Dasar Campak pada Bayi di Wilayah Kerja Puskesmas Padang Bulan Tahun 2019.

Diketahui bahwa dari 51 responden dengan kategori mendukung, mayoritas responden menjawab ya sebanyak 50 orang $(98,0 \%)$ dan minoritas responden menjawab tidak adalah sebanyak 1 responden $(2,0 \%)$. Dari 24 responden dengan kategori tidak mendukung adalah sebanyak 24 responden (100\%) adalah menjawab tidak.

Berdasarkan observasi yang dilakukan peneliti menyimpulkan bahwa Sikap Mendukung (Supportif) memiliki hubungan Dengan Kinerja Kader Imunisasi Dasar Campak Pada Bayi di Wilayah Kerja Puskesmas Padang Bulan.

Hasil penelitian ini sejalan dengan penelitian Marliana dkk (2015) di Puskesmas Perkotaan Rasimah Ahmad merupakan salah satu Puskesmas diKota Bukittinggi yang terletak di Jl. Umar Gafar Kecamatan Guguak PanjangKelurahan Aua Tajungkang Tangah Sawah Kota Bukittinggi denga judul faktor-faktor yang mempengaruhi kinerja kader posyandu dalam kegiatan imunisasi dasar lengkap di wilayah kerja puskesmas perkotaan rasimah ahmad dengan sampel sebanyak 85 orang dengan menggunakan pendekatan cross sectional terdapat nilai $p$ value $=$ $0,015$ ( $p<0,05)$. Menyatakan bahwa terdapat hubungan yang signifikan antara Sikap Mendukung (Supportif) dengan Kinerja Kader di Puskesmas Perkotaan Rasimah Ahmad.

Berdasarkan tabel diatas dapat dilihat bahwa Sikap Mendukung (Supportif) dari kader sudah baik namun masih ada yang tidak mendukung ini disebabkan oleh kurangnya sikap mendukung antara pemimpin dengan kader. Pemimpin jarang memberikan motivasi dan pelatihan kepada para kader atau kurang mendukung apa yang dilakukan para kader dikarenakan pemimpin terlalu membatasi sehingga terjadi kesenjangan antara pemimpin dengan kader dan antara para kader dengan kader lainnya sehingga rmengakibatkan kurangnya kinerja kader dilapangan.

Menurut asumsi peneliti hal tersebut membuktikan bahwa kinerja kader posyandu juga berhubungan dengan sikap mendukung. Berdasarkan hasil penelitian 
yang telah dilakukan bahwa Pemimpin itu harus memiliki rasa sikap mendukung (supportif) terhadap kinerja kader posyandu imunisasi, karena keaktifan kader juga dipengaruhi oleh rasa sikap mendukung baik itu dari dalam diri kader sendiri ataupun dari pihak luar. Pemimpin juga harus mengetahui alasan kader menjadi kader karena termotivasi pernah mengikuti penyuluhan dan termotivasi karena memiliki hubungan baik dengan kader lain pemimpin sebaiknya melakukan pertemuan antara seluruh kader supaya terjalin hubungan antara kader-kader posyandu dan yang paling terpenting selalu ada komunikasi antara pemimpin dengan para kader supaya pemimpin tau ada tidaknya permasalahan yang dihadapi kader sewaktu posyandu berjalan dilapangan.

\section{KESIMPULAN}

Ada hubungan Keterbukaan (Openness) di Wilayah Kerja Puskesmas Padang Bulan Tahun 2019 nilai $p$-value = 0,00 ( $p<0,05$ ). Ada hubungan Empati (Empaty) dengan Kinerja Kader Imunisasi Dasar Campak Pada Bayi di Wilayah Kerja Puskesmas Padang Bulan Tahun 2019 nilai $p$-value $=0,00(p<0,05)$. Ada hubungan Sikap Mendukung (Supportif) di Wilayah Kerja Puskesmas Padang Bulan Tahun 2019 nilai $p$-value $=0,00(\mathrm{p}<0,05)$.

\section{DAFTAR PUSTAKA}

Ade. 2017. Hubungan Sikap, Empati dan Motivasi Kerja dengan Kinerja Kader Posyandu di Kabupaten Ponorogo. Institut Pertanian Bogor. Bandung.

Deddy, Mulyadi. 2018. Perilaku Organisasi dan Kepemimpinan Pelayanan. Alfabeta. Bandung.

Marlina, Andriani dan Puadi. 2015. Faktorfaktor yang Mempengaruhi Kinerja Kader Posyandu dalam Kegiatan

\section{Imunisasi Dasar Lengkap di Wilayah Kerja Puskesmas Perkotaan Rasimah Ahmad Tahun 2015. Stikes Yarsi Sumbar Bukittinggi. Padang.}

Noer, Endah Pracoyo., dkk. 2013. Sero Survei Status Kekebalan Camapak Hasil Riskesdas. 2013. Kementerian Kesehatan RI. Jakarta.

Notoadmojo, S. 2012. Metologi Penelitian Kesehatan. Rineka Cipta. Jakarta

Nurfitriani. 2010. Faktor-faktor yang Mempengaruhi Keaktifan Kader Posyandu di Puskesmas Tanete. Universitas Islam Negeri Alauddin. Makassar.

Profil Puskesmas Padang Bulan. 2019. 